\title{
Pterygium excision with conjunctival autografting: an effective and safe technique
}

\author{
Bruce D S Allan, Perry Short, Geoffrey J Crawford, Graham D Barrett, Ian J Constable
}

\begin{abstract}
The optimum mode of treatment for symptomatic pterygia would combine efficacy (a low recurrence rate) with safety (freedom from sight threatening complications), and would not affect visual acuity adversely. The efficacy of pterygium excision with conjunctival autografting in a sun exposed population in which pterygia are prevalent has previously been questioned. A cross sectional review of 93 eyes of 85 patients was carried out by slit-lamp examination a minimum of 6 months (range 676 months) after pterygium excision and free conjunctival autografting. Case notes were reviewed to obtain details of complications and visual acuity changes related to surgery. Of six recurrences $(6.5 \%)$ four of these were asymptomatic with minor recurrences. Two patterns of recurrence were identified: cross graft recurrence (three cases) and outflanking (three cases). Complications (wound dehiscence, three cases; Tenon's granuloma one case; conjunctival cyst, one case) were all corrected by minor surgical revision without sequelae. Unaided acuities were unchanged or improved 3 months after surgery in 86 cases, with a minor diminution (1 Snellen line) in seven cases. This study demonstrates a low recurrence rate for a safe technique in an area in which ongoing ultraviolet light exposure levels are high and pterygia are prevalent.
\end{abstract}

(Br F Ophthalmol 1993; 77: 698-701)

Symptomatic pterygia are prevalent throughout the world in climates where ultraviolet exposure levels are high. Considerable debate exists with regard to their management.

A recent cross sectional study of the results of pterygium excision in Queensland, ${ }^{2}$ Australia found an overall recurrence rate of $46 \%$ after a 1-7 year follow up period. A variety of techniques (not including conjunctival autografting) were used, with a similar recurrence rate in each. Kenyon et $\mathrm{al}^{3}$ in 1985, in a comprehensive report of pterygium excision with conjunctival autografting (Fig 1), found a recurrence rate of $5 \cdot 3 \%$ (3/57) in patients with recurrent or advanced pterygia. But this study emanated from Boston where ultraviolet levels are relatively low. A smaller survey from the Carribean ${ }^{4}$ (19 patients) revealed a $16 \%$ recurrence rate (3/19 patients) using this technique, indicating that a higher recurrence rate may exist in populations with ongoing exposure to high ultraviolet light levels. Because of the risk of visually disabling complications associated with adjunctive chemotherapy $^{56}$ and radiotherapy, ${ }^{6-9}$ and the high recurrence rate after simple excision, ${ }^{210}$ pterygium excision with conjunctival autograft- ing has been adopted as the treatment of choice for primary, as well as recurrent, pterygia in Western Australia. A cross sectional study of the results from this method is presented below, together with an analysis of the extent and pattern of recurrence, and a review of complications.

\section{Methods and materials}

\section{SURGICAL TECHNIQUE}

The technique used was essentially similar to that described by Kenyon $e t a l^{3}$ with the following modifications, described in detail elsewhere ${ }^{11}:$ (1) subconjunctival anaesthesia (1\% lignocaine with adrenaline administered via a 30 gauge needle) was used throughout, ocular motility was thus preserved and the patient's gaze was directed to expose the surgical field without fixation sutures; (2) peripheral to central dissection was used during pterygium excision, aiming to preserve a superficial plane of cleavage between the lesion and the subjacent corneal stroma; (3) to preserve vascularity in the graft bed, cautery was minimised, and a diamond burr was not used in the defect left by excision; (4) to help ensure the correct tissue orientation, the free graft was spread out on the cornea and transferred to the excision defect (Fig 1) without lifting the graft clear at any point; (5) the graft was secured with two interrupted sutures through the limbal corners of the defect, and simple conjunctival apposition without deep bites through the sclera thereafter (8/0 Vicryl sutures were used initially, and $10 / 0$ nylon was used in later cases).

A gentian violet marker was used to delineate the trapezoidal donor site, the shorter limbal side

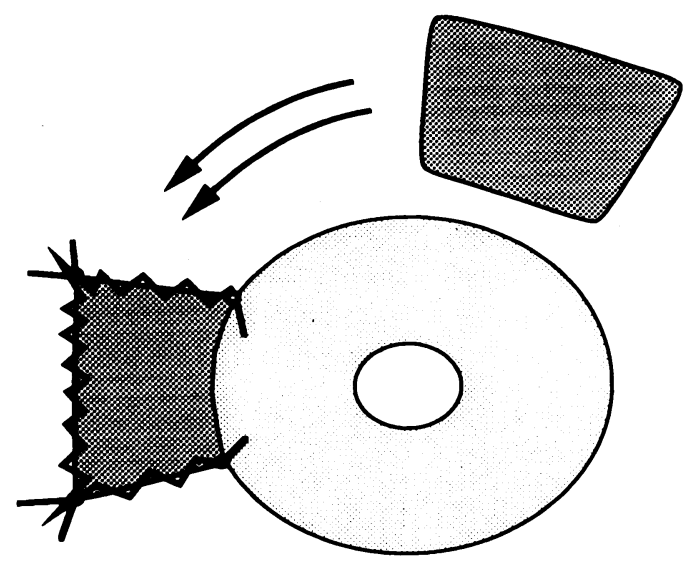

Figure 1 A schematic illustration of pterygium excision and conjunctival grafting. A free conjunctival graft is taken from the superolateral, subtarsal aspect of the bulbar conjunctiva approximately $1.5 \mathrm{~mm}$ posterior to the limbus and secured in the defect created by pterygium excision. The donor area is simply left to regenerate. 


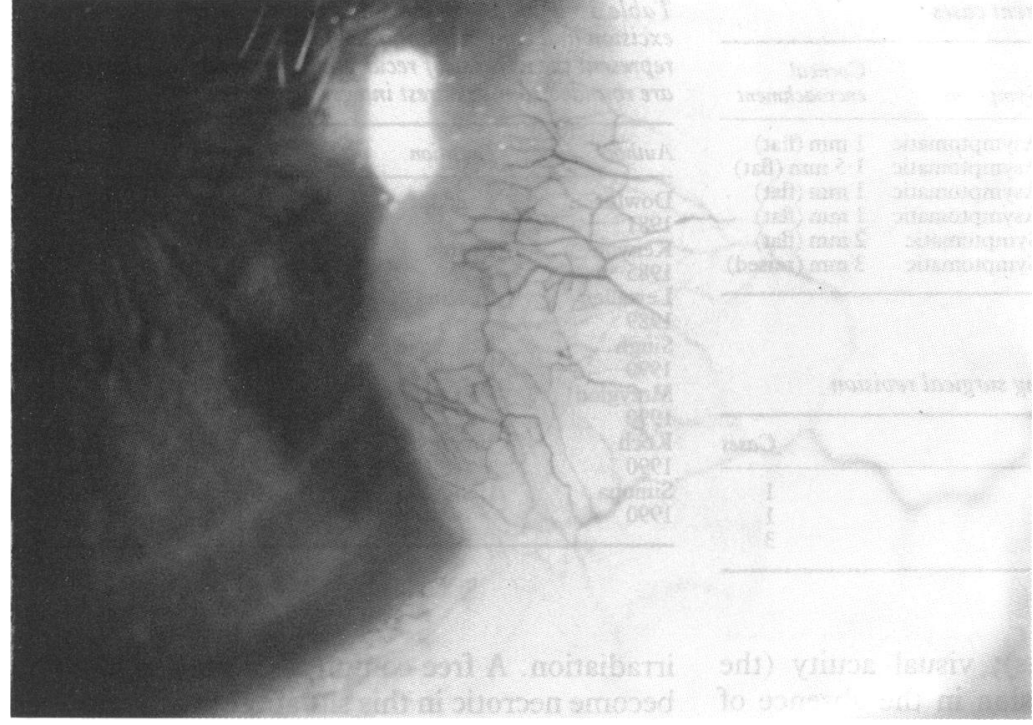

Figure 2A Cross graft recurrence. The pterygium has recurred directly across the graft (arrows). Cross graft recurrence should not graft recurrence should not
be confused with minor, superficial vascularisation of the cornea adjacent to the graft, which is frequently seen.

Figure 2B Outflanking recurrence. This pattern, in which the pterygium appears to grow back around the edge of the graft was described by Starck et al and illustrates the importance of not undersizing the graft.

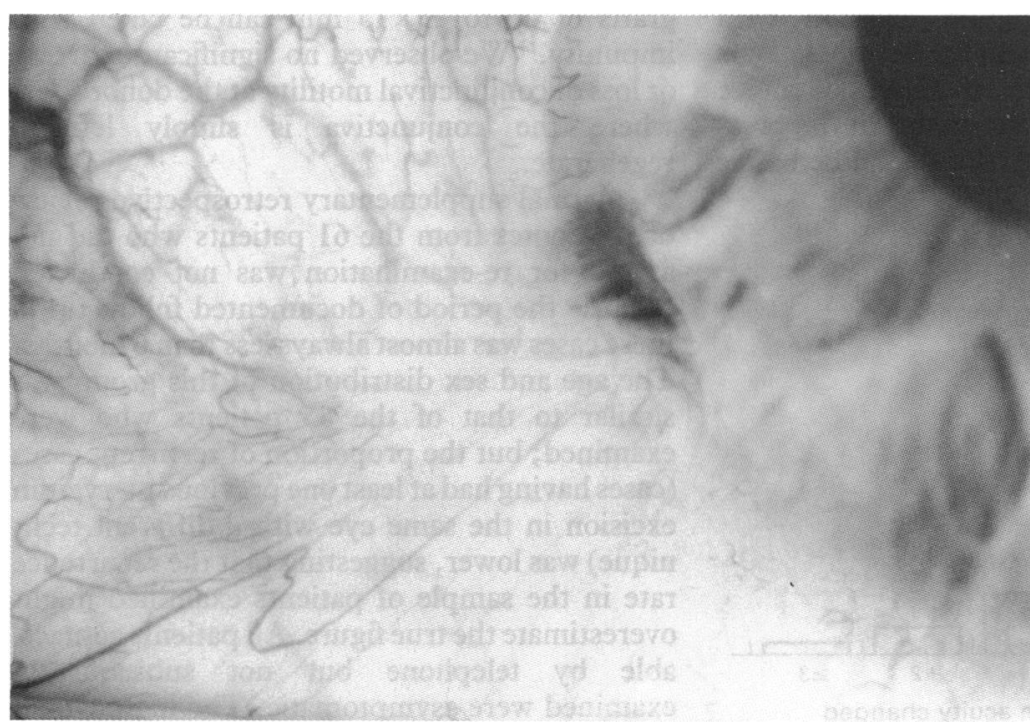

We adopted the definition of recurrence used by Sebban and Hirst': 'the formation of a wing of fibrovascular tissue occurring at the position of a previously excised pterygium with the apex crossing the limbus and extending onto the cornea,' as distinct from 'simple vascularisation of the corneal stroma.' Recurrences were further classified as symptomatic or asymptomatic, and photographed to define the pattern of recurrence in relation to the graft.

The notes of patients requiring further surgery to the same eye following pterygium excision were examined to determine the incidence and nature of complications requiring additional corrective surgery after pterygium excision and conjunctival autografting.

Preoperative and 3 month postoperative uncorrected visual acuities were also recorded retrospectively, as an index of the visual outcome of surgery. of which was measured to fit the limbal aspect of the pterygium excision site, and located approximately $1.5 \mathrm{~mm}$ posterior to the limbus superolaterally. Although the exact location of limbal stem cells is not known, ${ }^{12}$ the majority should be left intact at the donor site by graft excision with this method. Graft size is limited by restricted surgical exposure where the donor site is located further posteriorly, as described by Vastine et al..$^{13}$

CROSS SECTIONAL STUDY

Records of patients undergoing pterygium surgery with conjunctival autografting in Perth between 1985 and 1991 were reviewed. Records were retrieved from the Lions Eye Institute, the Sir Charles Gairdener Hospital, and Royal Perth Hospital. All patients still living in the Perth metropolitan area ( $\geqslant 6$ months after surgery) were contacted by telephone or by post, and asked to attend a voluntary follow up examination. Those who were able to attend were examined by one investigator (BDSA) using a Haag-Streit 900 slit-lamp for signs of pterygium recurrence.

\section{Results}

Slit-lamp examination was performed on 93 eyes of 85 patients (average age at surgery 49 years; range 22-85; male/female 46/39) who attended for voluntary review. The average time since surgery was 20 months (range 6-76 months). Twenty seven of the eyes ( $29 \%$ ) treated had had previous pterygium surgery at least once using another technique. A further 61 patients $(65$ eyes) (average age at surgery 44: range 24-78; male/female $36 / 25$ ) could not be traced (24 patients), had died (seven patients), or did not attend for re-examination (30 patients). Previous pterygium surgery had been performed on 11 eyes $(17 \%)$ in this group. None of the latter 30 patients (33 eyes), contacted by telephone, expressed dissatisfaction with the results of surgery or had persisting ocular surface discomfort.

A total of six recurrences $(6.5 \%)$, four asymptomatic and two symptomatic, were found. Two distinct patterns were identified: cross graft recurrence (Fig 2A) in three cases, and outflanking (Fig 2B) in three cases. All but one of these patients had had at least one previous pterygium excision. Age at surgery was similarly distributed in both recurrent and non-recurrent cases (Table 1). Recurrences were generally flat and uninflamed.

Corrective surgery for minor complications after pterygium excision and conjunctival autografting was required in five cases (Table 2). None of these went on to develop a recurrence.

Visual acuities were not affected by surgery in the majority of cases (Fig 3). Unaided acuity at 3 months had deteriorated by 1 Snellen line in comparison with the preoperative level in seven cases, improved by 1 line in 12 cases, and by 2 lines in five cases. In two cases, in which the pterygium had been encroaching upon the visual axis preoperatively, a marked improvement in acuity ( $\geqslant 3$ lines) was seen.

\section{Discussion}

The various techniques of excision available for pterygia may be evaluated with reference to three principal criteria: safety (freedom from sight 
Table 1 Some features of recurrent cases

\begin{tabular}{cllll}
\hline Age & $\begin{array}{l}\text { Previous } \\
\text { excisions }\end{array}$ & $\begin{array}{l}\text { Recurrence } \\
\text { pattern }\end{array}$ & Symptoms & $\begin{array}{l}\text { Corneal } \\
\text { encroachment }\end{array}$ \\
\hline 75 & 1 & Outflanking & Asymptomatic & 1 mm (flat) \\
32 & 1 & Outflanking & Asymptomatic & $1.5 \mathrm{~mm}$ (flat) \\
25 & 0 & Cross graft & Asymptomatic & 1 mm (flat) \\
60 & 1 & Outflanking & Asymptomatic & 1 mm (flat) \\
36 & 2 & Cross graft & Symptomatic & 2 mm (flat) \\
57 & 3 & Cross graft & Symptomatic & $3 \mathrm{~mm}$ (raised) \\
\hline
\end{tabular}

Table 2 Complications requiring surgical revision

\begin{tabular}{ll}
\hline Complication & Cases \\
\hline Excision of Tenon's granuloma & 1 \\
Excision of conjunctival cyst & 1 \\
Repair of wound dehiscence & 3 \\
\hline
\end{tabular}

threatening complications); visual acuity (the effect of treatment on vision in the absence of complications); and efficacy (freedom from recurrence).

Complications from pterygium excision and conjunctival autografting in this study (Table 2) were infrequent and easily rectified by further minor surgery. This concurs with a previous discussion of the spectrum of complications associated with this technique by Starck et al. ${ }^{14}$ In contrast with adjunctive topical chemotherapy ${ }^{56}$ or radiotherapy, ${ }^{7-9}$ no sight threatening complications have been reported.

Pterygia may compromise vision either by direct obscuration of the visual axis or, more commonly, through irregular astigmatism induced either by distortion of the cornea or the axial tear film. ${ }^{15}$ Conjunctival grafts heal rapidly $^{314}$ and would be unlikely to worsen induced astigmatism. Visual acuities were unchanged or improved in all but seven of the patients reviewed here. Random variation in acuity between examinations may partly explain the observed loss of one line of unaided acuity in these cases at 3 months after surgery, all of whom were asymptomatic and had no signs of recurrence. Pterygium excision with any technique may induce astigmatic changes however, particularly if care is not taken to dissect the pterygium away from the cornea in a superficial plane. Significant induced astigmatism, with a commensurate deterioration in unaided visual acuity, frequently follows pterygium excision with lamellar keratoplasty. ${ }^{16}$ Lamellar keratoplasty is none the less considered the treatment of choice in Western Australia for recurrence in the presence of a degenerate, avascular scleral bed after

Figure 3 Preoperative unaided visual acuity was compared with 3 month postoperative visual acuity. Unaided acuity was unchanged or improved in 86 of 93 cases.

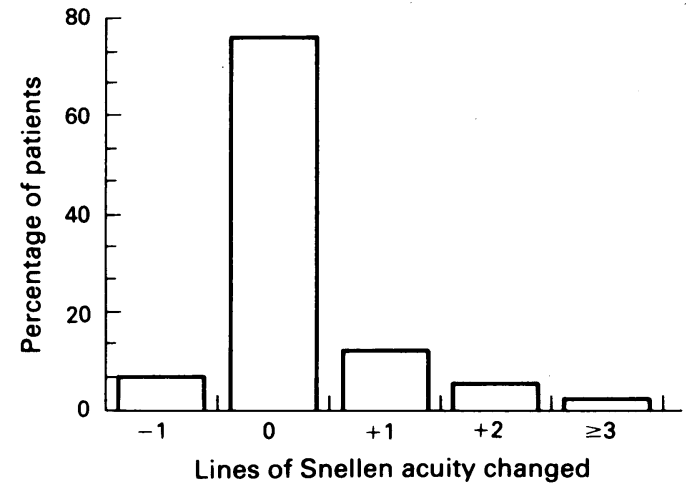

Table 3 Published rates of pterygium recurrence after excision and conjunctival autografting. Figures in brackets represent the number of recurrent cases observed. Percentages are rounded to the nearest integer

\begin{tabular}{lllc}
\hline Author & Location & Numbers & Recurrence \\
\hline $\begin{array}{l}\text { Dowlut } \\
\text { 1981 }\end{array}$ & Canada & 15 & $8 \%(1)$ \\
$\begin{array}{l}\text { Kenyon } \\
\text { 1985 }\end{array}$ & Boston & 57 & $5 \%(3)$ \\
$\begin{array}{l}\text { Lewallen } \\
\text { 1989 }\end{array}$ & St Kitts & 19 & $16 \%(3)$ \\
$\begin{array}{l}\text { Singh } \\
1990\end{array}$ & Los Angeles & 13 & $8 \%(1)$ \\
$\begin{array}{l}\text { Mrzyglod } \\
1990\end{array}$ & Poland & 41 & $3 \%(1)$ \\
$\begin{array}{l}\text { Koch } \\
\text { 1990 }\end{array}$ & Essen & 13 & $8 \%(1)$ \\
$\begin{array}{l}\text { Simona } \\
1990\end{array}$ & Geneva & 14 & $35 \%(5)$ \\
\hline
\end{tabular}

irradiation. A free conjunctival graft is likely to become necrotic in this situation. ${ }^{11}$

Recurrence rates reported ${ }^{2317-21}$ for pterygium excision with conjunctival autografting are generally low (Table 3). Variations in the results from a given technique may be influenced by a number of factors including: variations within techniques, the proportion of recurrent cases operated on, ${ }^{2}$ differences in postoperative medication, ${ }^{1}$ the age and location of the population studied, ${ }^{4}$ the length of follow up, and the definition of recurrence employed. ${ }^{2}$ Although later recurrences may occur, ${ }^{2}$ prospective observation $\mathrm{s}^{48}$ indicate that the majority will be apparent within the first 3 months. A minimum follow up period of 6 months should thus avoid a significant underestimation of the recurrence rate. Topical steroid and antibiotic medication was used routinely after surgery. Surgery was performed by a number of surgeons in addition to the authors, 23 in total including 14 ophthalmologists in training. Although the technique was essentially uniform and similar to that previously described, ${ }^{313}$ potentially significant variations may have occurred with the evolution of experience in pterygium excision and conjunctival autografting. Starck et al ${ }^{14}$ comment on the importance of taking a graft of adequate size. The observation of three cases in which a pterygium appeared to have recurred around the edge of the graft (outflanking) suggests that larger grafts may help to protect from recurrence. Conjunctival grafts of up to $15 \times 15 \mathrm{~mm}$ can be taken with impunity. ${ }^{12}$ We observed no significant scarring or loss of conjunctival motility at the donor sites, where the conjunctiva is simply left to regenerate.

A formal supplementary retrospective review of case notes from the 61 patients who did not attend for re-examination was not conducted because the period of documented follow up in these cases was almost always less than 6 months. The age and sex distribution of this group was similar to that of the 85 patients who were examined; but the proportion of recurrent cases (cases having had at least one previous pterygium excision in the same eye with a different technique) was lower, suggesting that the recurrence rate in the sample of patients examined might overestimate the true figure. All patients contactable by telephone but not subsequently examined were asymptomatic. The high overall 
proportion of cases that were asymptomatic (91 of 93 eyes examined and 33 of 33 eyes from 30 patients contacted by telephone: 124/126; $98 \cdot 5 \%$ ) is a noteworthy testament to the efficacy of this technique in practical terms - since minor asymptomatic recurrences have very little clinical relevance.

This study demonstrates a low recurrence rate from pterygium excision and conjunctival autografting in a predominantly white group in an area in which pterygia are prevalent and ultraviolet light levels are high. This technique is free from sight threatening complications (unlike topical chemotherapy or radiotherapy) and has no manifest deleterious effect on visual acuity (unlike lamellar grafting).

Conjunctival autografting is a technically undemanding but relatively slow procedure, often taking at least an hour to perform. Good results ${ }^{22}{ }^{23}$ have recently been described, although not universally, ${ }^{2}$ for other techniques of conjunctival mobilisation and closure after pterygium excision which may be more expedient. These techniques should also be safe, and should not reduce visual acuity. A prospective study, stratified for factors (such as patient age, and previous surgery) which might affect the likelihood of recurrence, would be required to determine whether free conjunctival autografting has any real advantage over other techniques of conjunctival closure after pterygium excision.

Presented in part at the Royal Australian College of Ophthalmologists' Annual Scientific Meeting, Sydney, October 1992.

1 Jaros PA, DeLuise V. Pingueculae and pterygia. Surv Ophthalmol 1988; 32: 41-9.

2 Sebban A, Hirst LW. Pterygium recurrence rate at The Princess Alexandra Hospital. Aust NZ f Ophthalmol 1991; 19: 203-6.

3 Kenyon KR, Wagoner MD, Hettinger ME. Conjunctival autograft transplantation for advanced pterygium and recur rent pterygium. Ophthalmology 1985; 92: 1461-70.
4 Lewallen S. A randomised trial of conjunctival autografting for pterygium in the tropics. Ophthalmology 1989; 96: 1612-4.
Rubinfeld RS, Pfister RR, Stein RM, Foster CS, Martin NF, Stoleru S, et al. Serious complications of topical mitomycin C
Subinfeld RS, Pfister RR, Stein RM, Foster CS, Martin NF, after pterygium surgery. Ophthalmology 1992; 99: 1647-54.

6 Farrel PL, Smith RE. Bacterial corneoscleritis complicating pterygium excision. Am f Ophthalmol 1989; 107: 515-7.

7 Tarr KH, Constable IJ. Late complications of pterygium treatment. Br f Ophthalmol 1980; 64: 496-505.

8 MacKenzie FD, Hirst LW, Kynaston B, Bain C. Recurrence rate and complications after beta irradiation for pterygia. Ophthalmology 1991; 98: 1776-80.

9 Moriarty AP, Crawford GJ, McAllister IL, Constable IJ. Severe ocular infection complicating beta irradiation induced scleral necrosis following pterygium excision. Arch Ophthalmol 1993; in press.

10 Youngson RM. Recurrence of pterygium after excision. Br J Ophthalmol 1972; 56: 120-5.

11 Allan BDS, Crawford GJ, Barrett GD, Constable IJ Pterygium excision and conjunctival autografting: a modified technique. Aust NZ F Ophthalmol 1993; in press.

12 Thoft RA, Wiley LA, Sundarraj N. The multipotential cells of the limbus. Eye 1989; 3: 109-13.

13 Vastine DW, Stewart WB, Schwab IR. Reconstruction of the periocular mucous membrane by autologous conjunctival transplantation. Ophthalmology 1982; 89: 1072-81.

14 Starck T, Kenyon KR, Serrano F. Conjunctival autograft for primary and recurrent pterygia: surgical technique and problem management. Cormea 1991; 10: 196-2.

15 Oldenburg JB, Garbus J, McDonnell JM, McDonnel PJ. Conjunctival pterygia: mechanism of corneal topographic changes. Comea 1990; 9: 200-4.

16 Simona F, Tabatabay CA, Leuenberger PM. Lamellar corneal graft in the treatment of pterygium: a ten year retrospective study of the recurrence and changes of astigmatism. Frf Ophthalmol 1988; 11: 759-63.

17 Dowlut MS, Laflamme MY, Les Pterygions recidivants: frequence et correction par autogreffe conjunctivale. frequence et correction par aut

18 Singh G, Wilson MR, Foster CS. Long-term follow-up study of mitomycin eye drops as adjunctive treatment of pterygia and its comparison with conjunctival autograft transplantation. Cornea 1990; 9: 331-4.

19 Mrzyglod S, Skubiszewska T. Surgery for pterygium with transplantation of an epithelial conjunctival flap. Klin Oczna 1990; 92: 99-100.

20 Koch JM, Mellin JB, Waubke TN. Initial experience with autologous conjunctival transplantation in pterygium. Klin Monatsbl Augenheilkd 1990; 197: 106-9.

21 Simona F, Tabatabay CA, Leuenberger PM. Preliminary results of pterygium excision with conjunctival autografting. Klin Monatsbl Augenheilkd 1990; 196: 295-7.

22 Anduze AL. Merest sclera technique for primary pterygium Anduze AL. Merest sclera technique for prim
surgery. Ophthalmic Surg 1989; 20: 892-4.

23 McCoombes J, Hirst LW, Isbell GP. Recurrence rate following simple excision and sliding conjunctival flap for primary ing simple excision and sliding conjunctival flap for primary pterygium. Presented at the Annual Scientific Congress of
the Royal Australian College of Ophthalmologists. Sydney, November, 1992. 